\title{
Cephalic vasomotor responses as indices of the orienting reflex, the defensive reflex, and semantic conditioning and generalization: A failure to replicate Soviet research ${ }^{1}$
}

\section{S. JOYCE BROTSKY, San Fernando Valley State College, Northridge, Calif. 91324}

Semantic conditioning and generalization were investigated through the auditory presentation of 15 or more CS-US pairings, interspersed among neutral words. The CSs were car brand names, and the US was I sec of white noise which followed the CS by $10 \mathrm{sec}$. The cephalic vasomotor responses (VR) of 47 Ss provided the data. Despite the fact that 45 of the Ss had demorstrated both conditioning and generalization when GSR or verbal reports were used as data, VRs provided no evidence for conditioning or generalization. The predicted change from vasodilation $(O R)$ to vasoconstriction (DR) did not occur, and the $O R$ was not related to subsequent VRs or the GSR to the first stimulus. The results and conclusions were in accord with those of Raskin, Kotses, \& Bever (in press), rather than predictions based on Soviet research.

Following the research of Soviet investigators (Luria \& Vinogradova, 1959; Sokolov, 1963), Maltzman and his colleagues (Brotsky, Raskin, \& Maltzman, 1963; Maltzman \& Raskin, 1965; Raskin, 1969) have used peripheral vasomotor constriction as an index of the $O R$ as well as an index of semantic conditioning and generalization. The Soviet formulation also predicts that a change in stimulation initially produces an $O R$ defined as a constrictive vasomotor response at the periphery and a dilatory vasomotor response at the temporal artery. Repeated stimulation should result in habituation of the OR, but, if the stimuli are intense or noxious, the cephalic OR is purported to give way to the DR, a constriction of the blood vessels of the forehead.

The present report attempted to provide evidence to determine (1) if the cephalic vasomotor response is an adequate predictor of semantic conditioning and generalization; and (2) if cephalic dilation habituates over the course of presentations of a noxious US, eventually giving way to cephalic vasoconstriction.

\section{METHOD}

The Ss were 23 male and 24 female undergraduates from UCLA. The data from these Ss were chosen from the data provided by the $200 \mathrm{Ss}$ who participated in a conditioning experiment reported elsewhere (Brotsky, 1968), since these Ss belonged to those subgroups who were given 15 or more CS-US pairings during training.

Vasomotor activity was measured by a Starling Corporation photoelectric plethysmograph attached to the forehead with Scotch electrical tape and secured with an elasticized headband. Vasomotor activity was continuously recorded (dc) on a Sanborn 320 at a paper speed of $1 \mathrm{~mm} / \mathrm{sec}^{2}$ Stimuli were prerecorded on magnetic tape and presented to Ss via Calrad SHP earphones. All equipment was located in a room adjoining Ss' room, and $E$ observed $S s$ through a one-way mirror.

The stimulus tape consisted of three parts: (1) a habituation list consisting of 19 neutral words, (2) a training list consisting of the conditioning trials embedded in a list of neutral words taken from the Connecticut Norms (Bousfield, Cohen, Whitmarsh, \& Kincaid, 1961), and (3) a generalization test list. A different training list was used for each of the six subgroups whose data are included in this report, although the habituation list and the generalization test list were identical for all Ss. The three parts followed in sequence without interruption.

A conditioning trial consisted of a CS word followed by the US, 1 sec of 100-dB white noise, measured at the earphones by a General Radio Sound level meter. The CS-US interval from the onset of the CS to the onset of the US was $10 \mathrm{sec}$, and the interval between successive stimuli varied from $10-15 \mathrm{sec}$. A constant background noise of $60 \mathrm{~dB}$ masked extraneous noises.

The CS words were the following five brand names of cars, always presented to Ss in the same order: OLDSMOBILE, PLYMOUTH, PONTIAC, MERCURY, and FORD. All six groups had at least 15 CS-US trials: (1) Group 5.5, five different CS words, each reinforced five times (25 trials) (2) Group 5-4, five different CS words, each reinforced four times (20 trials) (3) Group 5-3, five different $C S$ words, each reinforced three times (15 trials); (4) Group 4-5, four different CS words, each reinforced five times (20 trials) (5) Group 4-4, four different CS words, each reinforced four times (16 trials); and (6) Group 3-5, three different CS words, each reinforced five times ( 15 trials).
When $S$ arrived for the experiment, he was seated in a comfortable chair; the $E$ attached the pickups, read the instructions, placed the earphones on $S$, and left the room. The stimulus tape was started, and the first word appeared $1.5 \mathrm{~min}$ later. Following the conditioning experiment, $S$ was questioned regarding the experiment and was required to complete the Pittsburgh Revision of the Manifest Anxiety Scale (Bendig, 1956).

$$
\text { RESULTS }
$$

The vasomotor response (VR) was scored on a beat-by-beat basis, beginning with three beats prior to stimulus onset through the first $8 \mathrm{sec}$ following stimulus onset, measured at the diastolic level for each beat. The VR was expressed as a change from the average of the three beats prior to stimulus onset (resting level) to the average of the three most extreme beats of the first response, corrected for amplifier gain. The onset of a response was determined by a change in direction of the basal level following stimulus onset.

All VRs were scored by two readers, naive to the experimental hypotheses, whose readings were in agreement within $1 \mathrm{~mm}$ at least $90 \%$ of the time. All disagreements were settled by the two readers in consultation with the author.

The VR to the first stimulus word, BLOSSOM $(M=2.9 \mathrm{~mm})$, and to the first two USs $(M 1=2.9 \mathrm{~mm}, \quad M 2=2.9 \mathrm{~mm})$, were primarily vasodilations, although the direction and size of VRs to succeeding USs and verbal stimuli were inconsistent. Visual scanning of the records suggested that different $S$ s displayed a fairly consistent VR pattern, but careful application of the scoring rules failed to provide a basis for differentiation of Ss producing different VR patterns. The mean VRs to the USs averaged over blocks of two trials are presented in Table 1. Inspection of the data indicated that, although habituation of the OR was rapid, the OR was not succeeded by the DR, at least by the measurement techniques employed in the present study for 15 to 25 US presentations of $100-\mathrm{dB}$ white noise. The average of the mean VRs to the verbal stimuli, both CSs and neutral words, was close to zero, reflecting small inconsistent VRs.

Since the OR to the first word, when indexed by the GSR (Brotsky, 1968) or finger VR (Brotsky, Raskin, \& Maltzman, 1963) was highly correlated with subsequent responses, the product-moment correlations between the OR to BLOSSOM and the OR to the first US, the first CS, the control word that preceded the first CS, the final CS, and the generalization test word, CAR, were computed. No correlation approached statistical significance $(r= \pm .10)$. Moreover, the correlation between the VR to BLOSSOM and the GSR 
Table 1

The Mean Unconditioned Vasomotor Response of $47 \mathrm{Ss}$ to 1 Sec of $100 \mathrm{~dB}$ White Noise Measured in $\mathrm{mm}$ of Pen Deflection for Two Trial Blocks

\begin{tabular}{|c|c|c|c|c|c|c|c|c|c|c|c|c|c|}
\hline Block & 1 & 2 & 3 & 4 & 5 & 6 & 7 & 8 & 9 & 10 & 11 & 12 & 13 \\
\hline $\mathrm{mm}$ & 2.9 & 1.3 & 1.6 & 0.5 & 0.8 & -0.1 & 0.4 & -0.1 & 0.8 & 0.3 & 0.0 & 0.7 & -0.1 \\
\hline
\end{tabular}

to BLOSSOM was close to zero.

The mean VR to the first CS was $.6 \mathrm{~mm}$, the mean VR to the control word preceding the last CS was $-.3 \mathrm{~mm}$, and the mean VR to the final CS was $.2 \mathrm{~mm}$. Since all readings were taken to the nearest millimeter, mean differences of less than $1 \mathrm{~mm}$ could not be regarded as reliable, and no statistical tests seemed warranted. Thus, the data provided no evidence for semantic conditioning or for semantic generalization. Although 45 of the 47 Ss indicated on a postexperimental semantic differential that CAR was QUITE UNPLEASANT or VERY UNPLEASANT (control Ss had rated CAR as SLIGHTLY PLEASANT), the VR to CAR ( $M=0 \mathrm{~mm})$ was very similar to the VR to the preceding neutral word, SONG $(\mathrm{M}=.6 \mathrm{~mm})$. Although the OR to both BLOSSOM and to US1 was larger for females than for males, the differences were not statistically reliable $[F(1,45)=1.44, p>.05]$. No differential response patterns emerged for $S s$ who provided high, medium, or low scores on the anxiety scale. Since 45 of the 47 Ss who provided data for the present experiment had indicated on a postexperimental questionnaire that they were aware of the contingencies of the experiment, and since 46 of the 47 Ss had exhibited classical conditioning of the GSR to the verbal concepts employed, the failure to find evidence for classical conditioning or generalization cast doubt upon the usefulness of the VR as an index of semantic conditioning or generalization.

\section{DISCUSSION}

The scoring of the polygraph records presented considerable difficulty, despite the fact that prolonged training of the readers finally resulted in excellent reliability. Three separate scoring rules were initially adopted, and the first 12 records were scored according to the three separate systems. Although there was variation in individual scores as a function of scoring rule, the general results did not vary. In some cases, there was a definite constriction or dilation that could reliably be identified as the VR, but, in other cases, there were multiple changes in direction that could be interpreted as a series of responses or as a single biphasic response. The scoring rule that was finally adopted to define the VR was followed'by the readers, despite the fact that following the rule occasionally resulted in scores that seemed inconsistent with the general impression derived from visual inspection of the polygraph record.
Although the first verbal stimulus and the first four USs produced vasodilations, there was no evidence that these responses were replaced by vasoconstrictions following repeated stimulations. Thus, the predicted switch from ORs to DRs failed to occur, and there was no conclusive evidence that DRs were manifested in the cephalic vasomotor response. Although the data of an additional 152 Ss were available, there seemed no likelihood that the essential results would have been altered on the basis of the inclusion of additional data. These results were quite similar to those reported by Raskin and his colleagues (Raskin et al, in press). On the basis of these data, it may be concluded that the forehead VR, under the conditions of the present research, fails to provide an adequate index for reliably differentiating ORs from DRs or an adequate index for assessing semantic conditioning or generalization.

\section{REFERENCES}

BENDIG, A. W. The development of a short form of the MAS. Joumal of Consulting Psychology, $1956,20,384$

BOUSFIELD, W. A., COHEN, B. H. WHITMARSH, C. A., \& KINCAID, W. D Connecticut free associational norms. Technical Report No. 35, University of Connecticut, Contract Nonr 631(00), Office of Naval Research, 1961.

BROTSKY, S. J. Classical conditioning of the

\section{DAVID J. KING, State University College, Oswego, N.Y. 13126}

Eighty Ss were divided among eight treatment groups in a 2 by 2 by 2 design. The main effects were delayed auditory feedback is immediate auditory feedback $(D A F$ vs $I A F)$ learning of connected discourse, $D A F$ us $I A F$ recall of the previously read material, and sex. Accuracy of recall was influenced only by the $D A F$ vs IAF learning condition. DAF apparently influences only the learning and not the recall processes. Implications of these results were also examined regarding the question of the influence of distractability in producing the DAF-induced memory loss. galvanic skin response to verbal concepts. Journal of Experimental Psychology, 1968, 76, 244-253.

BROTSKY, S. J., RASKIN, D.C., \& MALTZMAN, I. The orienting reaction, semantic conditioning, and generalization of a vasomotor response. Paper read at Western Psychological Association, Santa Monica, Calif., 1963.

LURIA, A. R., \& VINOGRADOVA, O. S. An objective investigation of the dynamics of semantic systems. British Journal of Psychology, 1959, 50, 89-105.

MALTZMAN, I., \& RASKIN, D. C. The effects of individual differences in the orienting reflex on conditioning and complex processes. Journal of Experimental Research in Personality, 1965, 1 , 1-16.

RASKIN, D. C. Semantic conditioning and generalization of autonomic responses. Joumal of Experimental Psychology, 1969, 79, 69-76.

RASKIN, D, C., KOTSES, H., \& BEVER, J. Cephalic vasomotor and heart rate measures of orienting and defensive reflexes. Psychophysiology, in press.

SOKOLOV, E. N. Perception of the conditioned reflex. New York: Macmillan, 1963.

\section{NOTES}

1. This report is based on a $\mathrm{PhD}$ dissertation submitted to the University of California, Los Angeles. Facilities and partial support were provided by USPHS Grant No. MH-04684-02; Irving Maltzman was the principal investigator. The report was written during the writer's tenure as NIH Special Fellow in Human Development, 1968, Harvard University. Thanks are due to Irving Maltzman and to David Raskin for assistance and encouragement, and to Nancy Black and to Janet Morgan who helped with data analy sis.

2. Circular zinc electrodes were attached to the center of Ss' palms with plastic clips to pick up GSR activity. Results based on GSR data, as well as on verbal reports for $200 \mathrm{Ss}$, were reported in full in an earlier paper (Brotsky, 1968). Fortyeight Ss received 15 or more CS-US trials, but since the VRs of one $S$ were unreadable due to equipment failure, the present report is based on data for $47 \mathrm{Ss}$.

\section{The retention of connected discourse presented and recalled under delayed auditory feedback}

The reliable experimental production of forgetting of connected discourse has been most difficult. Despite reports of success (Slamecka, 1960a, b), the utilization of reasonable everyday learning materials and procedures frequently results in negative findings (King \& Tannenbaum, 1963). There seems to be a possibility that the technique of delayed auditory feedback may prove to be a tool capable of producing forgetting of connected discourse. Several experiments (King, 1963; King \& Walker, 1965) have demonstrated poorer retention of connected discourse when the material is practiced under DAF as contrasted with the control condition of IAF.

Recent experiments have also shown 